\title{
Exploring an Active Learning Focus in a Liberal Arts Engineering Curriculum
}

\section{Dr. David Robert Bruce P.E., Fulbright University Vietnam}

Dr. Bruce has a passion for technology development with a focus on empowering society through altering perception and perspective. He holds a B.A.Sc. in Environmental Engineering from the University of Waterloo, an M.A.Sc. in Materials Science \& Engineering from McMaster University, and a Ph.D. in Chemical and Biological Engineering from the University of British Columbia. This varied engineering education has taught him to view our world through a multifaceted lens. Dr. Bruce has studied and worked in the alternative energy field for 15 years in a variety of disciplines, with industrial experience in both large tech companies and start-ups. Dr. Bruce is keen to share his understanding into underlying physical science and how to use it to actualize engineering and bring innovation from conception to production. Dr. Bruce is an avid sculptor, painter, and photographer and he hopes to pioneer integration of fine arts with engineering at Fulbright to help examine what serendipitous discoveries can be found through these combined fields.

\section{Dr. Sebastian Dziallas, Fulbright University Vietnam}

Sebastian Dziallas is a Founding Faculty Member at Fulbright University Vietnam in Ho Chi Minh City. He completed his PhD work in the Computing Education Research Group at the University of Kent. His research examines characteristics of computer science graduates and uses a highly qualitative, narrative methodology to explore the sense graduates make of their own educational experiences within their wider learning trajectories. Before joining the University of Kent, he graduated from Olin College of Engineering in the United States. 


\title{
Exploring an Active Learning Focus in a Liberal Arts Engineering Curriculum
}

\begin{abstract}
Fulbright University Vietnam is Vietnam's first not-for-profit, independent university with a focus on liberal arts, sciences and engineering undergraduate programs.

The curriculum is built on integration of these programs and incorporates active learning and experiential learning activities in courseware design. Experiential learning activities include student led research, examination of user centered design, and observational analysis of the environment. Active learning activities include think-pair-sharing, flipped classrooms, and sticky-note clustering. Complimentary to the active learning and experiential learning emphasis, the integration of engineering with liberal arts affords incorporation of concepts encompassing student-centric learning and allows community rather than content-based exploration of concepts.
\end{abstract}

The interdisciplinary core of the first-year program introduces students to topics spanning the arts, humanities, engineering, and the social, natural, and computational sciences. The initial engineering focused course, Creating \& Making, is focused on practicing skills in ideation, project scoping, project management, reporting, communicating, and other aspects of design methodology. The course content is community driven and while nucleated with concrete examples of course material from the instructors, allows the student body to explore and reflect upon the benefits and drawbacks of the provided examples and to organically investigate alternative approaches through their practice. In this approach, rather than outlining a discrete subset of material, the encompassed material is further refined with generational and cultural learning by the student community.

Combining many aspects of pedagogical development in such a unique facility poses a challenge in breakdown and analysis of the effectiveness of these methodologies and learning environments. Granularity in perceived student valuation of concepts were investigated through application of a retrospective survey applied twice per term. The survey analyzed concepts related to active learning, course content and liberal arts and compared them to one another. The survey results are broken down to analyze which concepts the students found to be of most value in their learning, and to evaluate if there are discrepancies between previously reported challenges in acceptance of liberal arts or active learning concepts in relation to this community. Complementary to this analysis is reflective qualitative remarks from the student body in the form of individual comments submitted after course completion. Through analysis of results the refinement of the programming in this unique first year interdisciplinary program can be further data driven and hopefully lead to improved understanding of the intricacies of combined liberal arts - active learning - engineering environments. 


\section{Introduction}

Education as a genre can be self-defined with a pedagogical dimension that is forever in search of further understanding. This ever-present shifting of perspective on variety and applicability of education styles has afforded an increasingly large combination of interdisciplinary institutions. Just as education diversifies as it is adapting to the growing understanding of learning styles and subjects of investigation, there is an increasing need for the plurality of institutional breadth as the industrial landscape continues to change.

Technology is allowing rapid global change; technology changes quickly, people change more slowly, culture changes even slower still [1]. Specialization in technical domains requires longterm dedication and an increasingly large resource pool to stay competitive. Technical and research focused school systems with a narrow focus can leverage industry support through research funding to supplement facility development. Alternatively, recognizing that technological shifts can be occurring faster than program development there should be a growing demand for generalist versus specialist education to better prepare students for greater range of employment skills from the multiple fields they will need for success [2].

Fulbright University Vietnam is Vietnam's first not-for-profit, independent university with a focus on liberal arts, sciences and engineering undergraduate programs. The breadth of university focus is designed to foster an experiential learning environment replete with active learning, multidisciplinary and co-operative educational experiences.

The advantages of liberal arts open-ended environment to provide for development of critical thinking and multi-generational learning are difficult to assess in a short timeframe. It has been shown that it often takes a prolonged timeline to capitalize on the financial benefits of a liberal arts education [3], however limiting the measured benefits of liberal arts learning to simply personal financial gain seems to naively constrain the genre. Revision of how we can measure success is not the focus of the as prepared article and will remain a debate for future discussion.

With a student-centric community learning focus there is debate regarding acceptance of such a free liberal arts approach. Vietnamese secondary and higher education has been traditionally framed with more rigid teaching methods and curricular constraints [4]. If the student body has been acclimatized to these conventional environments it is of interest to examine the perception and performance of the students in this new setting. The student body currently consists of students primarily aged 18-19 years old of exclusively Vietnamese descent with approximately a 60:40 female to male ratio. Further analysis of associative cultural factors of this community have not been evaluated.

The debate as to the acceptance and importance of active learning approaches has continued since inception [5]. Marrone et al. [6] have shown that some international students have a preference to active learning and additional merits of this learning approach for diverse student populations include unification of the student body and a better understanding of the complexities inherent in collaborative learning. Active learning not only engages material with intrinsic motivation and develops critical thinking and analysis skills to improve content comprehension, but also provides a safe, supporting, interactive environment to enhance 
application and understanding of theoretical concepts. Providing engaging activities have been shown to enhance student performance in traditional metrics, even if student perception of the activity contradicts the result [7]. Many of these active learning concepts share attributes with liberal arts environments, yet it would be beneficial to elucidate if there are unique challenges in aspects of these two education elements.

In addition to the educational benefit of a liberal arts environment and utilizing active learning elements there is underlying course content that students may find either engaging or uninteresting. Design of course content and curriculum has been traditionally segregated by discipline but is moving towards a more flexible conceptual framework. Accreditation bodies are realizing the multiple perspective benefits offered by greater diversity in outcomes-oriented approaches as we further examine what engineers do throughout society [8]. The content of the course in relation to active learning and liberal arts elements can be depicted the hierarchal diagram shown in Figure 1.

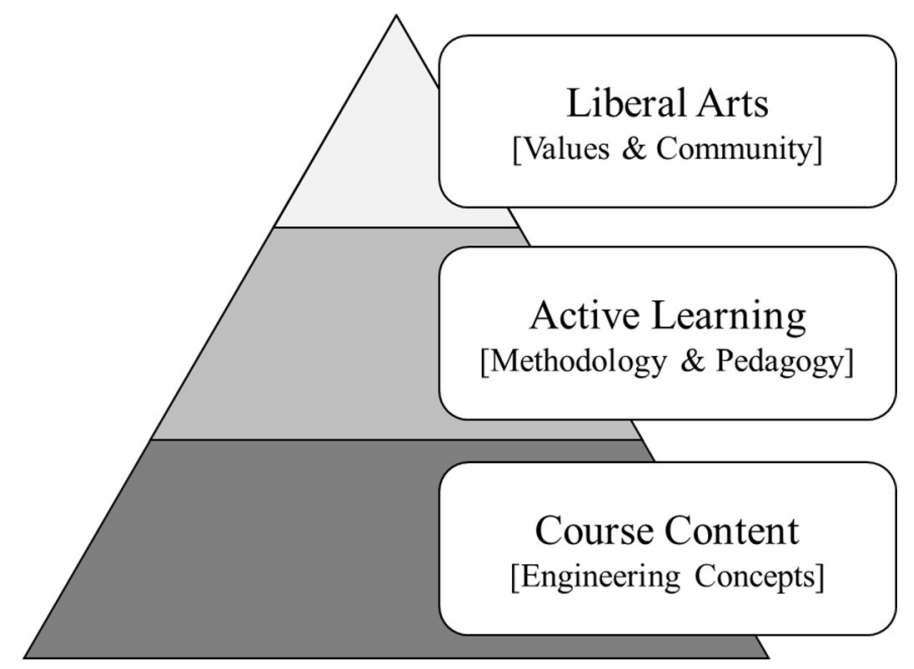

Figure 1 - Hierarchal Organization of Analytical Categories

The goal of this breakdown is to analyze which concepts the students found to be of most value in their learning, not a debate over their comparative value from a pedagogical sense. The goal is to evaluate if there are discrepancies between previously reported challenges in acceptance of liberal arts or active learning concepts in relation to this community and compare them to challenges in acceptance of engineering concepts for our mixed-discipline student cohort.

The sections of this paper include a literature investigated to frame the study, methodology employed for this investigation, observations and discussions regarding the applied survey and class feedback, and finally conclusions and follow-up steps planned.

\section{Background and Literature Review}

Defining Liberal arts in the $21^{\text {st }}$ century can have contentious connotation as it seems this concept is in search of new definition by which to enrobe modern perspectives on the use of the classic concepts of 'the free person'. In this discussion a description of the liberal arts provided by Daniel Weiss [9] has been drawn upon for conceptual elements of the liberal arts, but further 
categorized in terms of 'Intellectual Skills', 'Civic Elements' and 'Environmental Factors'. Intellectual skills can be defined by liberal arts concepts that are more active in terms of engagement with society, critical thinking, leadership, reflection, etc. Civic elements involve the humanistic subjects of study; passive characteristics of a liberal arts educated person. These can include morality, a sense of identity, community presence, and can also include spirituality. The Environmental factors defining a liberal arts experience include co-curricular and extracurricular exploration, and other activities that encourage more diverse or inclusive learning environment. This top-down division of concepts in liberal arts is no way meant to be comprehensive, but allows for a more clustered examination of active, passive and environmental attributes of the ethos. It is of interest if the student body views differences in this breakdown of these elements.

Active learning has been evolving since inception and continues to investigate student participation in their learning [5]. While there are many merits of these techniques, the criticism of the techniques have also been well documented [10] - [12]. The criticisms of active learning include that students dislike forced interaction, dislike the increased responsibility for their own learning, and prefer instruction solely from an expert perspective [7]. The distribution of criticisms of active learning techniques are adopted as identifying elements of their practice in the corresponding three categories: 'Increased Interaction', 'Increased Responsibility' and 'Decreased Expertise'. Decreased expertise in this context involves removal of the professor as the primary authority for information as presented from the peer-directed activity; their peers are viewed as having decreased expertise compared to the knowledge of the instructor. It is of interest if there is parity in the criticism of the presented active learning activities in the Fulbright student population.

Redesign of engineering curriculum has been traditionally segregated by discipline but would benefit with a more liberal arts conceptual framework as institutions adapt their programming when opportunities arise [8]. Accommodation of more generic and portable skillsets fall in line with a Liberal Arts framework of providing for an open canvas for student-led development with a community focus. Allowing students to interact as a community to practice using peer feedback in real time with instructor support could enhance opportunities for further "pedagogies of engagement" [13].

Institutions have been resistant to adopting a more progressive engineering curriculum based on an evolving system design even with concrete examples that show the benefits of a cognizant view of the ideas that define the discipline with increased involvement of an integrated community [14].

\section{Course Description}

At Fulbright, engineering concepts covered by the first-year course UG1070: Creating \& Making are focused on cross-disciplinary approaches. Focus on transferrable skills mixed with practical exposure highlight elements of design, human psychology, technology literacy, project planning, and project management. The design work incorporates primarily human centered design with other concepts of ideation and divergent thinking to spur innovation [1], [15]. Psychological 
concepts covered involve self-inquiry through Myers-Briggs and Jungian analyses and focused on investigating the emotional needs of society to drive engineering implementation [1]. Technology literacy examined concepts of mechanism design and simple machines, explored power electronics and automation, incorporated practice of simple and power tool use and then through to computer aided design and fabrication. Project planning focused on the documentation of design work, establishment of a team contract and communication charter and provided project feedback with use of regular design briefs. Project management primarily involved practice of Agile scrum/sprint methodology for tracking and organization of the applied coursework to employ methodologies of flexible iterative processes modelled after the Agile 'Software Development' Manifesto. The learning outcomes were to identify and select suitable design and fabrication tools and techniques to create simple engineering artifacts, to recognize the role of process and methodology in the design of basic engineering mechanisms, to evaluate their own performance as well as that of other team members and can communicate this feedback effectively, and to explain scientific and engineering principles of their work to a range of audiences. These learning outcomes related to the ABET learning outcomes of a general engineering program [16]. More generally these learning outcomes were classified as one of three categories to represent design, management, or communication program elements: 'Design, Ideation and Fabrication Skills', 'Project planning and Management Strategy', or 'Written and Oral Communication Skills'.

The first-year course is taken by all students at Fulbright in their first or second years as part of their core courseware. The organization of the course content is developed in a stagewise manner to allow for a simple introduction of design theory and project management followed by the recursive practice and continual development of the accrued concepts of the course as they are progressively introduced. Course content development incorporating recursive practice allows incremental stages of information expansion and feedback regenerated for subsequent iterations. A pictorial representation of the course organization is shown in Figure 2 with course content elements punctuated by student modules organized in three phases.

The course culminates with a final read-out where the students participate in a 'trade-show' atmosphere where they have the opportunity to present their projects to the general public and to answer questions about the societal problem they are addressing with their design work. In this inaugural year bamboo was chosen as a main design material because of its widespread use in construction in the region, ease of access to stock material, and to introduce the concept of enhancing value through materials processing. The scope of the societal problem was also limited, and the students were challenged to use sound as a signifier as a constraint in their device. 


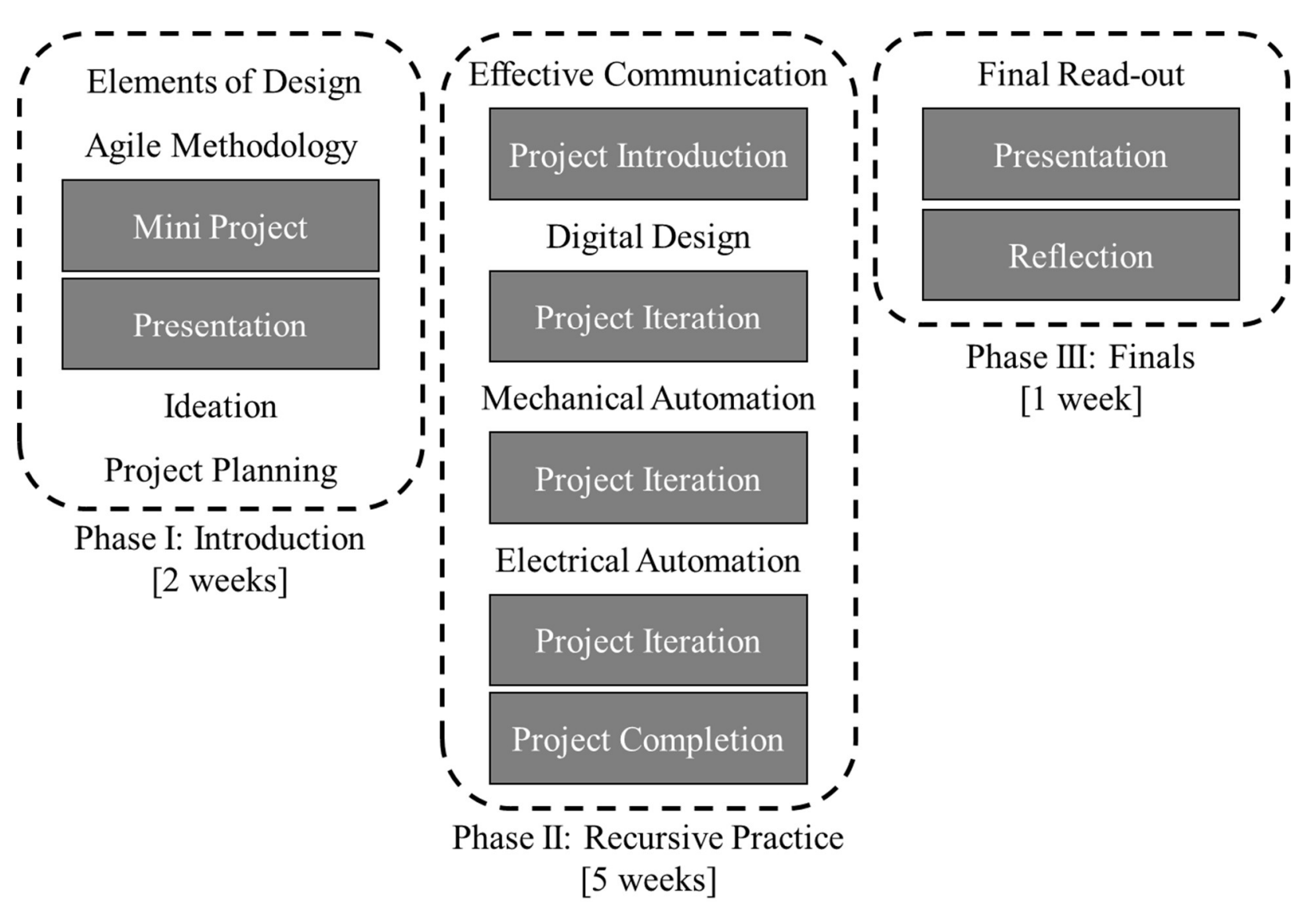

Figure 2 - Course Content Organization for UG1070: Creating \& Making.

\section{Methodology}

The analysis of the student performance was evaluated through two methods: A student survey probing the community preference of active learning-liberal arts-engineering concepts, and student reflections to the course experience.

\section{Student Survey}

The first analysis addressed the valuation of concepts investigated through application of a retrospective survey applied to the students twice per 8-week term: once mid-term and once at the end of the semester. The survey analyzed concepts related to active learning, course content, and liberal arts and compared them to one another. The 128 comparative statements were generated from articles analyzing breakdowns of active learning or liberal arts, or included content related to the course curriculum. The statements were randomized and distributed to 6 versions of the survey that included seven questions assigned to each student. Each question started with a polarizing factor, ie. 'I valued'/'I disliked', and followed with three statements that were to be evaluated in relation to one another, regardless of their perceived relative subject. The students ranked the three statements using an exponential scale of base 2 where the summation of the three values they gave the statements added up to 100 or less (eg. the 3 statements could be rated 64-2-16, but not 64-64-4). If the polarizing factor was a negative statement the values 
were converted to their analogous positive value through converting the value through the $\log _{2}$ relationship afterwards (ie. a value of 2 would become a value of 64 etc.). This scale was adopted in relation to the work of Posner \& Weyl to allow for more accurate polarization of how the dissimilar statements related to one another comparatively, previously used when comparing disparate attributes of candidates in political elections [17]. This exponential scale allows for increasing the distance between extremes in the options provided, but also shows there could be additional information to be gained by close examination of similar options through emphasizing relative local comparisons. In using this methodology, each grouping of statements not only had an absolute value, but also a relative value in relation to the neighboring values. It is hoped this granularity in the data will provide for increased breakdown utilizing machine learning methods as the data is further analyzed. This survey was utilized for two semesters on a total of 57 students (31 students Q1 and 26 students Q2 respectively).

Independent to the student survey results, the statements generated for the survey were also analyzed by the author as to their perceived agreement with elements of an active learning environment, values of a liberal arts community, or subjects of the applied course content. Complimentary to the assessment of if statements represented elements of an active learning, liberal arts, or engineering theme (or a combination of the groupings) the statements also were evaluated as to if they represented particular elements of each theme as discussed in the introduction and literature review.

Codification of the survey statements were performed independently by the author for both the alignment with the ascribed breakdown of elements of liberal arts, active learning and engineering course content as well as the as assigned particular elements of each theme. The statements categorization resulted in the following distribution shown in Figure 3.

Examples of statements for each categorization are shown in Table 1. A full breakdown of the survey statements will be released in a follow-up article examining the survey structure once more educators are consulted for their expert perspectives. This is done to eliminate bias from preliminary evaluations at this point. The survey results are broken down to discretize the elements of liberal arts from active learning and course content in order to better understand the combination of these program elements, and the results are then plotted to visually identify if the concepts can be further clustered or segregated. As the properties of the dataset are unknown, the uncertainty in their variability is represented by the coefficient of variation, a figure that divides the standard deviation of the measurement by the mean and helps to better illustrate the inhomogeneity in opinion for some statements. 


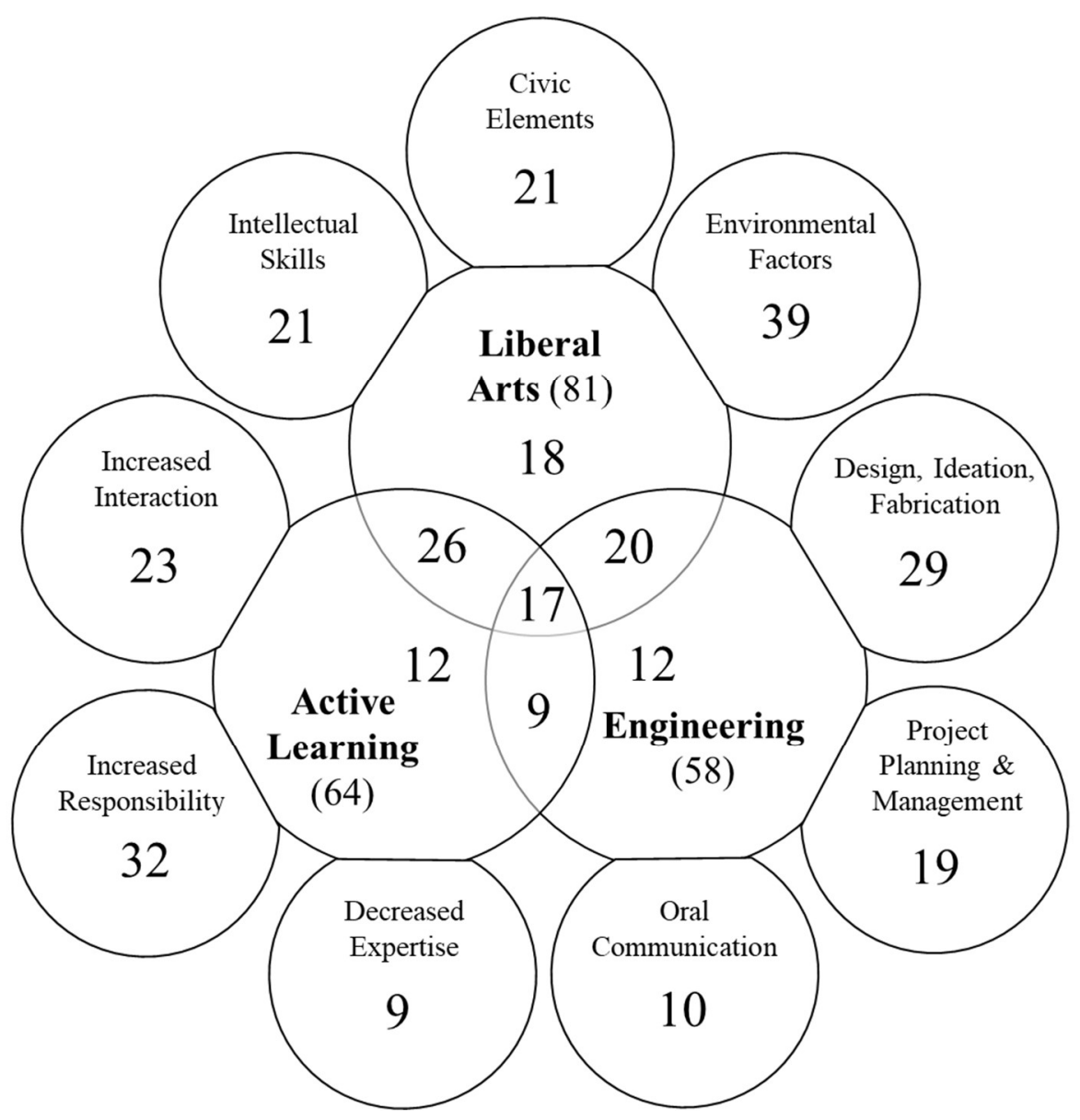

Figure 3 - Distribution of Survey Statements by Category. Segment numbers indicate the total statements represented in the survey

\section{Student Reflection}

Complementary to this student survey is reflective qualitative remarks from individual comments submitted after course completion. The individual comments were in the form of an open ended essay with the writing prompt framed with three questions: What are the things you really appreciated about the course or things that could have be done better, what are the concepts that you learned that you think will help you in your continued career at Fulbright (and beyond!), and what are the things that surprised you that you learned about yourself through your time in Creating \& Making.

Students wrote between 500 to 1500 words for their personal reflections and the information was then compiled and evaluated as to congruence with the breakdown of elements in active learning, liberal arts, or engineering curricular elements. The student reflection statistics are then compared with the results of the literature breakdown of acceptance to these categorical elements and were also compared to the results of the survey that assayed specific examples of crossover of these elements. The results are represented in a tabular format to represent the statistics of the student population. 


\begin{tabular}{|c|c|c|c|}
\hline Statement & $\begin{array}{l}\text { Active Learning } \\
\text { Element }\end{array}$ & $\begin{array}{l}\text { Liberal Arts } \\
\text { Element }\end{array}$ & $\begin{array}{l}\text { Engineering } \\
\text { Element }\end{array}$ \\
\hline Expansive brainstorming where we build upon ideas of others & $\begin{array}{c}\text { Increased } \\
\text { Interaction }\end{array}$ & $\begin{array}{l}\text { Intellectual } \\
\text { Skills }\end{array}$ & $\begin{array}{c}\text { Design, Ideation, and } \\
\text { Fabrication Skills }\end{array}$ \\
\hline Examining my hypotheses by engaging real-world data & $\begin{array}{c}\text { Increased } \\
\text { Responsibility }\end{array}$ & $\begin{array}{c}\text { Environmental } \\
\text { Factors }\end{array}$ & $\begin{array}{l}\text { Project Planning and } \\
\text { Management Strategy }\end{array}$ \\
\hline Considering the perspective of others & $\begin{array}{l}\text { Increased } \\
\text { Interaction }\end{array}$ & $\begin{array}{c}\text { Civic } \\
\text { Elements }\end{array}$ & $\begin{array}{c}\text { Written and Oral } \\
\text { Communication Skills }\end{array}$ \\
\hline Approaching my peers for answering my questions & $\begin{array}{l}\text { Increased } \\
\text { Interaction }\end{array}$ & $\begin{array}{c}\text { Environmental } \\
\text { Factors }\end{array}$ & \\
\hline Having my professor as a facilitator rather than lecturer & $\begin{array}{l}\text { Decreased } \\
\text { Expertise }\end{array}$ & $\begin{array}{c}\text { Environmental } \\
\text { Factors }\end{array}$ & \\
\hline Gaining self-confidence and self-understanding & $\begin{array}{c}\text { Increased } \\
\text { Responsibility }\end{array}$ & $\begin{array}{c}\text { Civic } \\
\text { Elements }\end{array}$ & \\
\hline Critical and reflective reading applied to my submitted work & $\begin{array}{c}\text { Increased } \\
\text { Responsibility }\end{array}$ & & $\begin{array}{l}\text { Project Planning and } \\
\text { Management Strategy }\end{array}$ \\
\hline Practicing effective oral and written communication skills & $\begin{array}{c}\text { Increased } \\
\text { Interaction } \\
\end{array}$ & & $\begin{array}{c}\text { Written and Oral } \\
\text { Communication Skills }\end{array}$ \\
\hline Recursive design practice & $\begin{array}{c}\text { Increased } \\
\text { Interaction }\end{array}$ & & $\begin{array}{c}\text { Design, Ideation, and } \\
\text { Fabrication Skills } \\
\end{array}$ \\
\hline Learning psychological concepts for our practical work & & $\begin{array}{c}\text { Civic } \\
\text { Elements }\end{array}$ & $\begin{array}{c}\text { Design, Ideation, and } \\
\text { Fabrication Skills } \\
\end{array}$ \\
\hline Getting my grade as a majority of my team co-operation & & $\begin{array}{c}\text { Intellectual } \\
\text { Skills }\end{array}$ & $\begin{array}{c}\text { Written and Oral } \\
\text { Communication Skills }\end{array}$ \\
\hline The benefit of these learned activities outside of engineering & & $\begin{array}{c}\text { Environmental } \\
\text { Factors }\end{array}$ & $\begin{array}{l}\text { Project Planning and } \\
\text { Management Strategy }\end{array}$ \\
\hline Using props for learning like sticky notes & $\begin{array}{c}\text { Increased } \\
\text { Interaction }\end{array}$ & & \\
\hline Reflecting on the gaps in my knowledge & $\begin{array}{c}\text { Increased } \\
\text { Responsibility }\end{array}$ & & \\
\hline In-depth student led tutorials & $\begin{array}{l}\text { Decreased } \\
\text { Expertise } \\
\end{array}$ & & \\
\hline Helping one another understand & & $\begin{array}{c}\text { Intellectual } \\
\text { Skills } \\
\end{array}$ & \\
\hline Seeing the diverse projects my peers are doing & & $\begin{array}{c}\text { Civic } \\
\text { Elements } \\
\end{array}$ & \\
\hline Having autonomy over my learning & & $\begin{array}{c}\text { Environmental } \\
\text { Factors } \\
\end{array}$ & \\
\hline Learning about new technologies & & & $\begin{array}{c}\text { Design, Ideation, and } \\
\text { Fabrication Skills } \\
\end{array}$ \\
\hline Learning about ways to organize my time & & & $\begin{array}{l}\text { Project Planning and } \\
\text { Management Strategy }\end{array}$ \\
\hline Learning about elements of business meetings & & & $\begin{array}{c}\text { Written and Oral } \\
\text { Communication Skills }\end{array}$ \\
\hline
\end{tabular}

Table 1 - Distribution of the Example Survey Statements

\section{Observations \& Discussion}

In the classroom, the students were subdivided into groups of 5-6 and these groups were formed for the entire duration of the course. The designed active learning activities in the course mainly consisted of think-pair-sharing, flipped classrooms, and sticky-note clustering. The think-pairsharing activities incorporated guided student work wherein student groups were able to discuss course elements intergroup and then their results compared with statements generated with other group projects. The examination of differing and similar challenges the groups faced enriched the activity by demonstrating the distribution of perspective amongst the results. The flipped classroom element of the course was designed where there was one members of each group that was also part of a separate 'Task Force' that prepared a lecture on one of the core course 
elements: Agile Methodology, Effective Communication, Digital Design, Mechanical Automation, or Electrical Automation. The students prepared the content for their sessions a week prior to their demonstration, with materials provided by the instructors in addition to other student-sourced resources. The content was delivered with active exercises as constructed by the students and included games, quizzes, tutorials on software and standard lecture. It was hoped this generational learning could direct a suitable platform for approach to the concepts with respect to the varied background of the student cohort. Sticky-note clustering was performed in mainly the ideation and project planning lectures to help explore ideas in both convergent and divergent ways. The project scope and direction of each student group was operated to allow for maximum freedom to explore the design process, the only provision was that groups track their direction using Agile methodology so as to allow a structured development cycle each week and deliver a design brief update to document their process and decision making.

\section{Survey Results}

The student survey was administered in the middle of their recursive practice as well as at the end of the course. The results are pooled and are shown in Figure 4 with the error bar representing the standard deviation between the four results of Q1 and Q2. In examination of the results it appears that the student perception of elements of each of the subdivisions were equivalent, with the exception of elements that were evaluated to be of an active learning nature without cross-association to engineering or liberal arts. As shown in Figure 5, when the results were distributed amongst division of elements of each area of study, the area of active learning that seems to be the least favored are statements that describe decreased expertise in instruction.

Summarized Survey Comparison between Correlated Active Learning, Liberal Arts, and Engineering Content

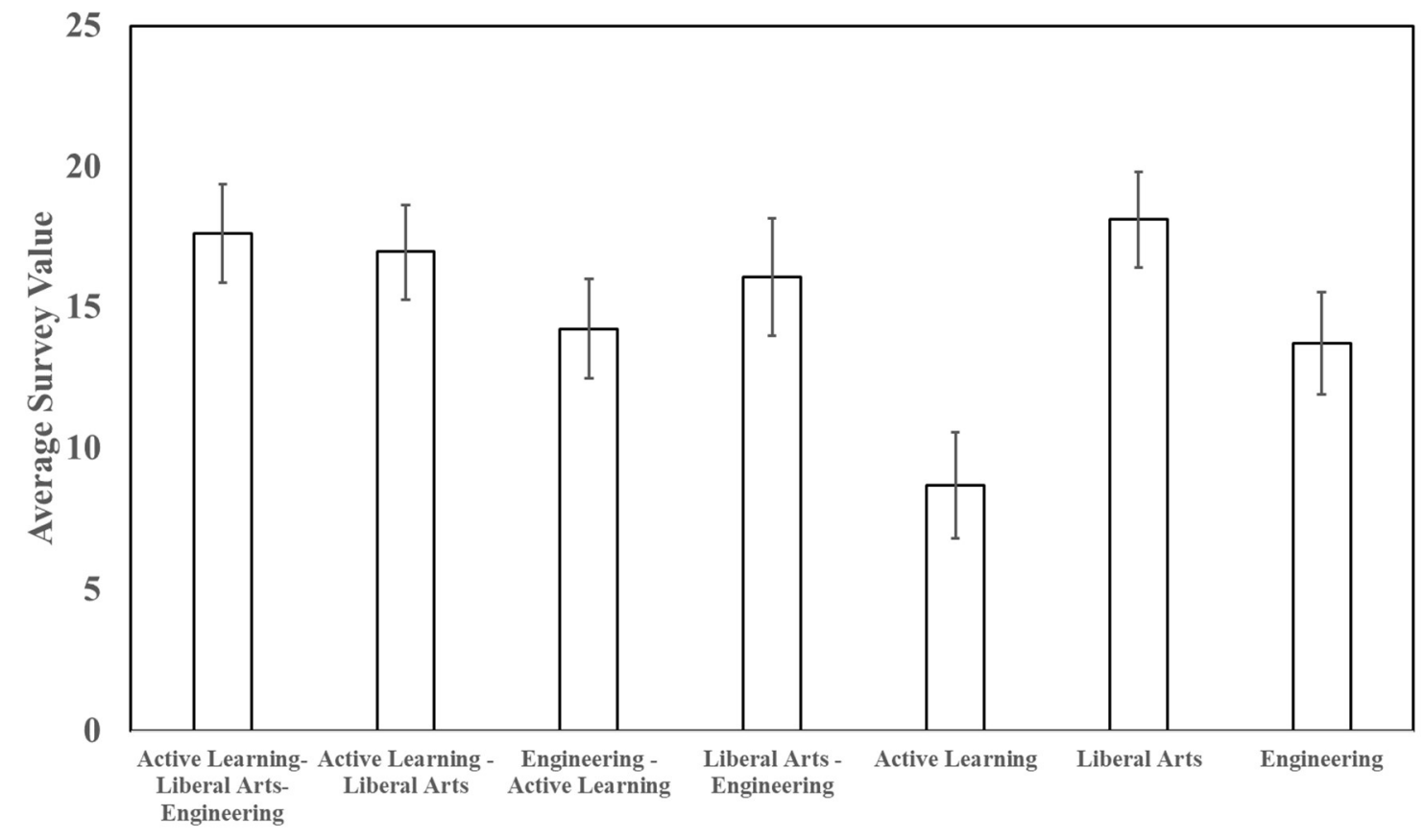

Figure 4 - Survey Results Showing Distribution of Correlated Active Learning - Liberal Arts and Engineering Elements 
Figure 5 also seems to indicate that there is some preference in engineering related content towards design, fabrication, ideation, project planning and management rather than communication skill development. A full breakdown of all the associated survey statements in regard with the correlated categories can be seen in Figures 6-12 in the Appendix.

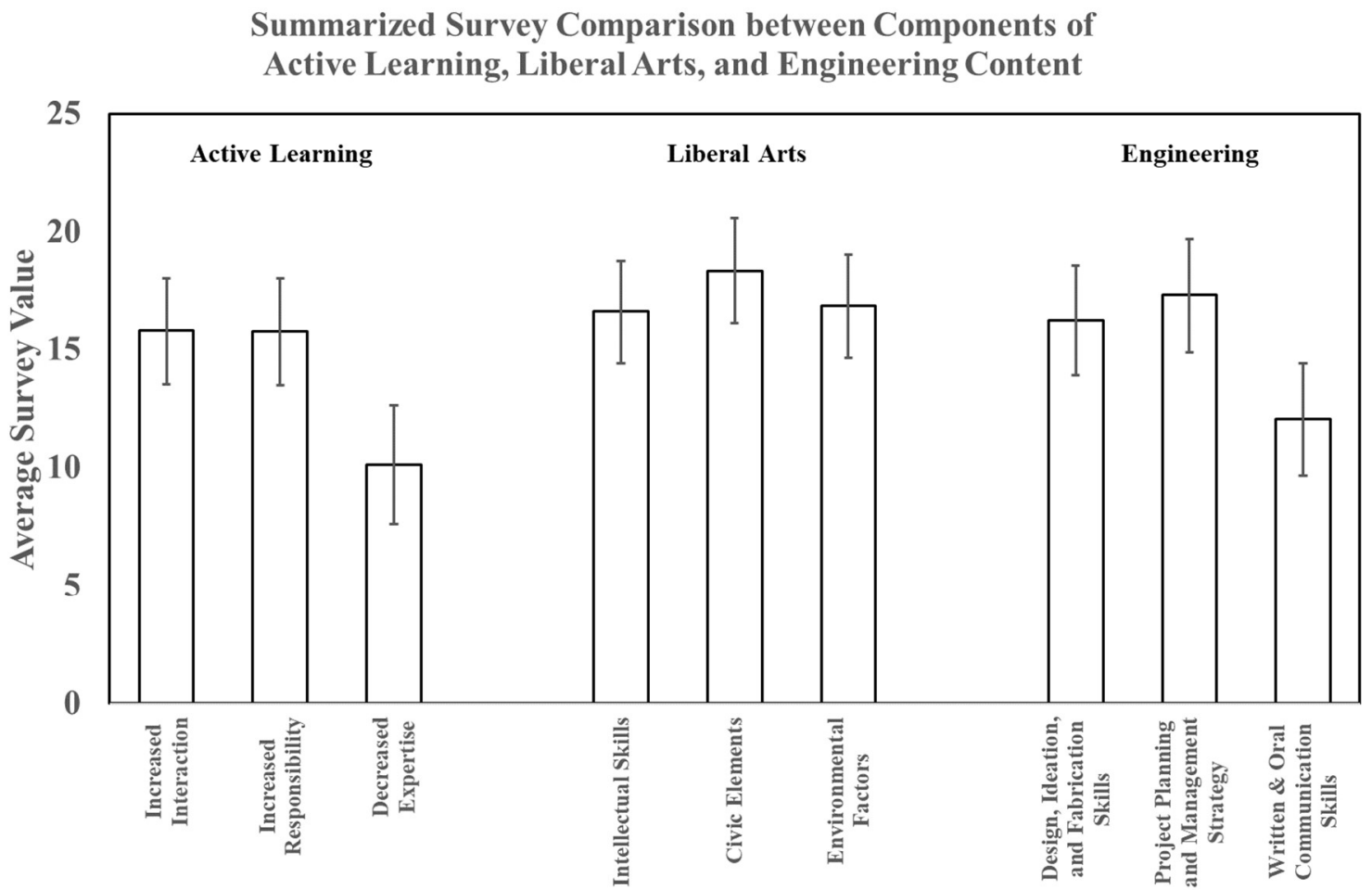

Figure 5 - Survey Results Showing Distribution of Components of Active Learning - Liberal Arts and Engineering Elements

With examination of Figures 6-12 details emerge regarding further information as correlated to the flipped classroom environment and peer learning that may provide additional context for the aversion to decreased expertise in instruction.

Peer learning group work elements were not evaluated negatively as shown in correlated Active Learning-Liberal Arts-Engineering statements, with high ranking and low variance of the statements: 'Working in collaboration with my classmates', 'Ability to be sensitive to others perspectives', and 'Ability to work as a team'(Figure 6). Statements 'Considering the perspective of others' and 'Group project work' were middling and this was correlated to lacking a Liberal Arts environment (Figure 8). The preference for group work disappears when students are 'Getting my grade as a majority of my team co-operation' and this was classified as when Active Learning direction was missing from the Liberal Arts-Engineering intersection (Figure 9).

Renouncement of the decrease in expertise in student instruction is clearly indicated where two of the lowest ranked statements included 'Finding elements of my learning' and 'Helping to design the learning examples' in association with the in-class activity of flipped classroom experiences (Figure 7). These statements were not directly correlated with Engineering elements 
and were considered products of Active Learning - Liberal Arts experiences. In the same Active Learning - Liberal Arts subset, several statements such as 'Getting feedback shared to others to help our learning', 'Having my professor as a facilitator rather than a lecturer', 'Approaching my peers for answering my questions' and 'Peer teaching' fell to above average scores, which indicates that there are still elements of group work that are attractive. These more positive statements perhaps correlate to a preference with these activities towards increased responsibility or peer interaction for this student community.

When examining statements that would be correlated to Active Learning environments uncorrelated with specific Engineering or Liberal Arts context, 'Not fully understanding what we are learning' and 'In depth student-led tutorials' both were amongst the $10 \%$ lowest scores globally, with the student-led tutorial statement having a low coefficient of variation indicating this was also uniformly agreed upon (Figure 10). In general, the active learning statements uncorrelated with Engineering or Liberal Arts were not well received, with 'short in-class demonstrations' indicating that if they are to be included, they are to be kept brief.

Siloed elements of Liberal Arts, and Engineering (Figures 11, 12) seem to show that time management and transferrable skills are of primary importance. The low evaluation and high variance of 'learning about engineering' is most likely representative of the mixed discipline academic cohort (Figure 12).

Further breakdown of the clustered elements of the survey are underway utilizing machine learning to better bifurcate organization of the statements and see if there are underlying trends. It is recognized that variation in the sorting of statements as to their discrete category should also be further analyzed as to get a more thorough breakdown of what constitutes the overlap of these concepts. Follow-up work in this regard is discussed as an ensuing study.

\section{Student Reflection Results}

It was found through the analysis of the student reflections shown in Table 2 that students most often commented on active learning elements of their experience $(91 \%)$, but also identified elements of liberal arts (64\%) and engineering (53\%) in their analysis. The statements were classified as to if they addressed positive or negative elements of the program, and when statements in a reflection were generated in both positive and negatives support, they were counted for both, hence additive percentages $>100 \%$ in this regard. 


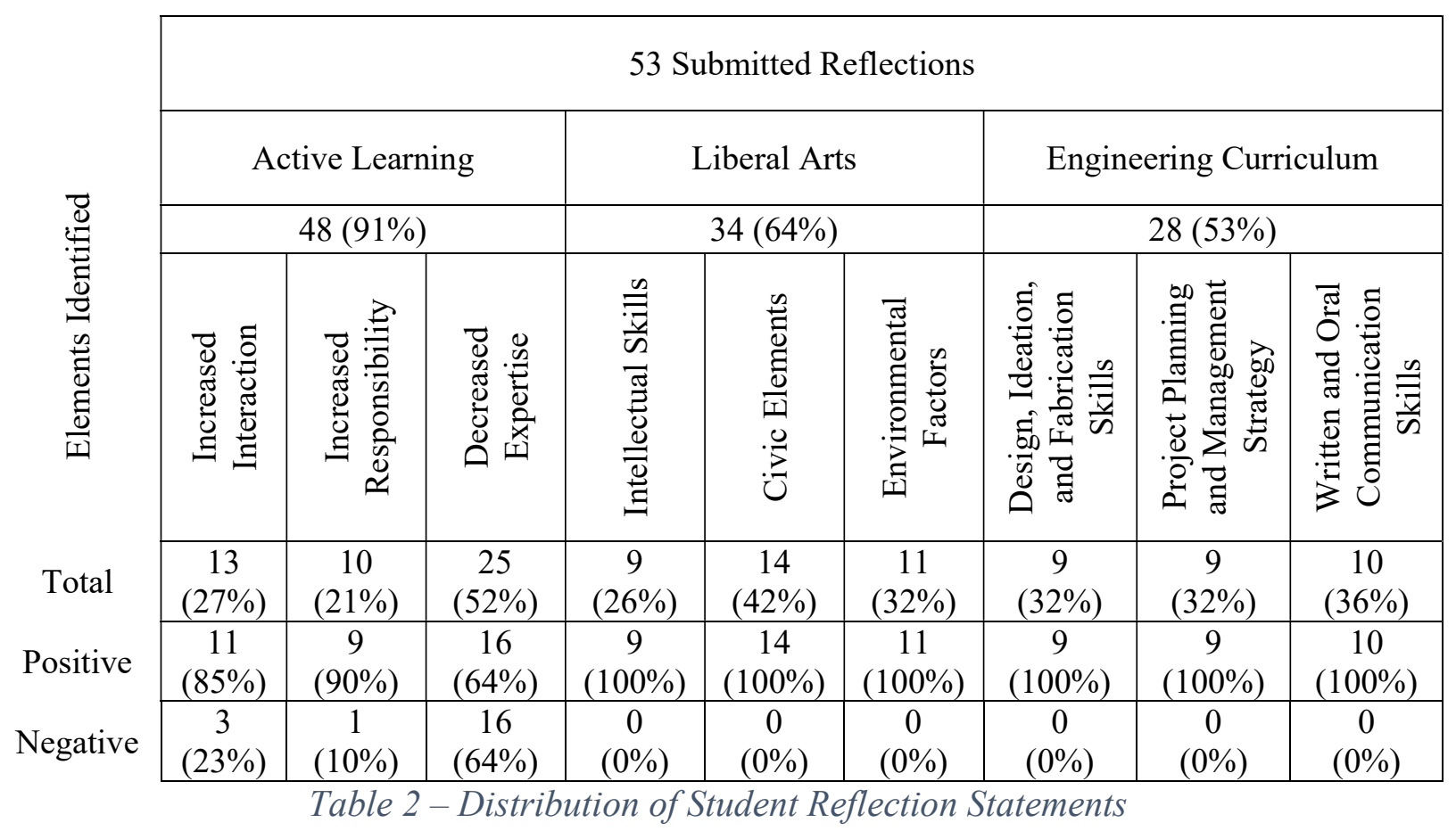

For active learning, the results of the student reflections seem to confirm the results found in the survey, with an overabundance of statements (52\%) addressing elements of decreased expertise as the subject matter. Of these statements however, there was an even division of statements that were negative and positive. Negative statements included 'information provided was rather overwhelming while the major takeaways were unclear', 'the workshop content prepared by students themselves are not deep and authentic enough', and 'presentations were not sufficient' whereas positive statements identified as 'helpful to learn the material and prepare a presentation which allowed us to re-learn, paraphrase, explain, and apply our knowledge', 'having task forces to co-teach a concept to the whole class makes the concepts more interesting and relatable as we are all co-learning them together', 'this serves as a very vibrant example of the power of selfresearching and self-learning', and 'the best way of learning is teaching others'. The reflections were written after all the surveys were conducted, so it is possible that in performing the reflection the students learned to appreciate the additional benefits of the flipped-classroom experience. The negative statements regarding decreased expertise of active learning can also seemingly be diminished by including the philosophy of a liberal arts environment. By focusing on community development and expectation of lifelong learning outside of the classroom it is not unreasonable to utilize the lack of lecture depth as a way to reinforce personal responsibility of the students to go out in search of deeper understanding if they seek it so long as that is emphasized in class and is directed as further study. There was overwhelmingly positive support for increased responsibility for personal learning and students remarked that 'the fact that we took full responsibility in facilitating the workshops (as well as doing our own projects) also happened to encourage a strong sense of student autonomy, ownership, and initiatives', 'embracing the uncertainty has a good effect because while I do not know what I am doing, I actually learn best and explore more about the field', and 'I love the way how the professors played the role of the instructors more than teachers. It gave us spaces to actively think, struggle 
and try to do something ourselves (...) I believe that is an essential habit for a learner to grow'. These statements give evidence that this may be an attractive approach to refute negative elements of decreased expertise in flipped classroom experiences through self-directed learning.

Supporting the argument of preference in active learning teamwork elements, statements involving increased interaction were overwhelmingly positive (85\%), and included reflections of 'Working in group was a great chance to cooperate and learn from each other', 'What kept me going is my teammates and possible learning experiences', and 'Dividing students to work in teams facilitated learning significantly. While being in a team, students interacted with each other and learn from the problems of it'. These positive statements are in strong agreement with the positive team-based elements of active learning found in the survey and might be more successful in international institutions to facilitate additional peer support and generational learning.

The liberal arts and engineering reflections were uniformly divided but interestingly did not hold negative connotation for any of the elements addressed. When presenting liberal arts concepts of intellectual skill development students praised lifelong learning, critical thinking and appreciated that 'students are required to figure out most things by themselves. Although this is, I can attest, tiring, in the long term it will turn out extremely beneficial. When students enter the workplace, they must come up with solutions based on real problems, so the skills honed throughout their college years can significantly help them thrive'. Reflections of civic elements focused on statements of self-understanding and being conscientious of one another's emotions and needs. Environmental factors discussed appreciation for interdisciplinary study and appreciation of other fields; one student remarked 'being willing to step out of our comfort-zone will definitely result in a better-qualified learning experience for everyone.' Benefits reflected on the engineering components focused mainly on the practicality of tool use and human-centered design elements as well as the transferability of the project management skills. Again appreciation of generational knowledge was reflected in the written and oral communication here as a student remarked 'I find that instead of sticking to theories and finding the right terms, it is easier for me to explain and for others to understand if I just use my own words.' In addition to these categorized positive aspects, the students expressed that exploration in this class also proved to be rewarding for breaking down gender roles and misconceptions on what it meant to be an engineer.

\section{Conclusions and Next Steps}

Data driven decisions can improve areas of focus for new learning environments. The analysis of this new active learning focused liberal arts environment for engineering study has provided an interesting examination of elements of each of these disparate areas. It was found that contrary to existing active learning literature, the students found team-based active learning and increased responsibility for their learning as enjoyable elements of the program. The students still found challenges in learning activities that incorporated decreased expertise in instruction but also reflected on many positive elements of the process in their reflections including more in-depth knowledge of self-study and the benefits of improving knowledge by teaching others. It is postulated that the liberal arts environment helps to refute such negative elements of flipped 
classroom experiences in this regard through the emphasis on self-directed learning and generational community learning.

It is of further interest in this study as to the longitudinal results of this environment. As the culture of the university continues to develop it is imperative that this community learning environment be maintained so that we can further explore this development. Analysis of similar structure in other Fulbright classes and the year over year changes in Creating \& Making will help to confirm further analysis of this initial finding.

Expansion of survey depth was identified as an area of improvement in this study. With the statements generated and evaluated by a sole researcher it is imperative to expand the dataset to gradate the distribution of what constitutes liberal arts, active learning and engineering elements. To refine this distribution a further survey will be conducted at the annual ASEE conference in order to survey a more sophisticated population of engineering education researchers.

\section{References}

[1] D.A. Norman, The Design of Everyday Things: Revised and Expanded Edition. New York: Basic Books, 2013.

[2] D. Epstein, Range: Why Generalists Triumph in a Specialized World. New York: Riverhead Books, 2019.

[3] A.P. Carnevale, B. Cheah, M. Van Der Werf, A First Try at ROI: Ranking 4,500 Colleges, Georgetown University Center on Education and the Workforce, 2020, [Online.] Available: https://cew.georgetown.edu/roi-of-liberal-arts-colleges-coverage-byreport/ [Accessed: 22-Jan-2020].

[4] T.T. Tuyett, "What Shapes the Passiveness in Learning of Vietnamese Students", VNU Journal of Education Research, vol. 29, no. 2, pp.71-83, 2013.

[5] C. Bonwell, J. Eison, "Active Learning: Creating Excitement in the Classroom", AEHE-ERIC Higher Education Report No. 1. Washington, D.C.: Jossey-Bass, 1991.

[6] M. Marrone, M. Taylor, M. Hammerle, "Do International Students Appreciate Active Learning in Lectures?", Australasian Journal of Information Systems, vol. 22, pp.1-14, 2018.

[7] L. Deslauriers, L.S. McCartya, K. Miller, K. Callaghan, G. Kestin, "Measuring actual learning versus feeling of learning in response to being actively engaged in the classroom", Proceedings of the National Academy of Science, vol. 116, no.39, pp. 19251-19257, 2019.

[8] M. Liebelt, S. Eglinton-Warner, W. Soong, S. Al-Sarawi, B. Ng, B. Phillips, M. Sorell, An Engineering Approach to Engineering Curriculum Design: 28th Australasian Association for Engineering Education (AAEE) Annual Conference (AAEE-2017), December 10-13, 2017, Manly, Sydney. 2018.

[9] E. Roalsvig, "Weiss stresses value of liberal arts education", The John Hopkins News-Letter, Nov. 3, 2016, [Online]. Available:

https://www.jhunewsletter.com/article/2016/11/weiss-stresses-value-of-liberal-artseducation/ [Accessed: 3-Dec-2019]. 
[10] R.M. Felder, R. Brent, "Navigating the bumpy road to student-centered instruction", College Teaching, vol. 44, no.2, pp. 43-47, 1996.

[11] A.P. Fagen, C.H. Crouch, E. Mazur, "Peer instruction: Results from a range of classrooms". The Physics Teacher, vol. 40, pp. 206-209, 2002.

[12] M. Vuorela, L. Nummenmaa, "How undergraduate students meet a new learning environment?”, Computers in Human Behavior, vol. 20, pp. 763-777, 2004.

[13] K.A. Smith, S.D. Sheppard, D.W. Johnson, R.T. Johnson, "Pedagogies of engagement: Classroom-based practices" Journal of Engineering Education, vol. 94, pp. 87-101, 2005.

[14] S.A. Ambrose, "Undergraduate Engineering Curriculum: The Ultimate Design Challenge", The Bridge - Linking Engineering and Society, The National Academy of Engineering, vol. 43, no. 2, pp.16-23, 2013.

[15] V. Papanek, Design for the Real World, New York: Bantam Books, pp. 23-41, 1973.

[16] “ABET Criteria for Accrediting Engineering Programs, 2018 - 2019”, [Online]. Available: https://www.abet.org/accreditation/accreditation-criteria/criteria-foraccreditingengineering-programs-2018-2019/ [Accessed: 14-Jan-2020]

[17] E.A. Posner, E.G. Weyl, Radical Markets - Uprooting Capitalism and Democracy for a Just Society, Princeton, NJ: Princeton University Press, pp. 80-126, 2018. 


\section{Appendix}

Figures $6-12$ associated with the analysis of individual statements segregated by Active Learning, Liberal Arts and Engineering elements are presented.

Their distribution is as follows:

Figure 6 - Breakdown of Active Learning - Liberal Arts - Engineering Survey Elements

Figure 7 - Breakdown of Active Learning - Liberal Arts Survey Elements

Figure 8 - Breakdown of Engineering - Active Learning Survey Elements

Figure 9 - Breakdown of Liberal Arts - Engineering Survey Elements

Figure 10 - Breakdown of Active Learning Survey Elements

Figure 11 - Breakdown of Liberal Arts Survey Elements

Figure 12 - Breakdown of Engineering Survey Elements 
Active Learning - Liberal Arts - Engineering

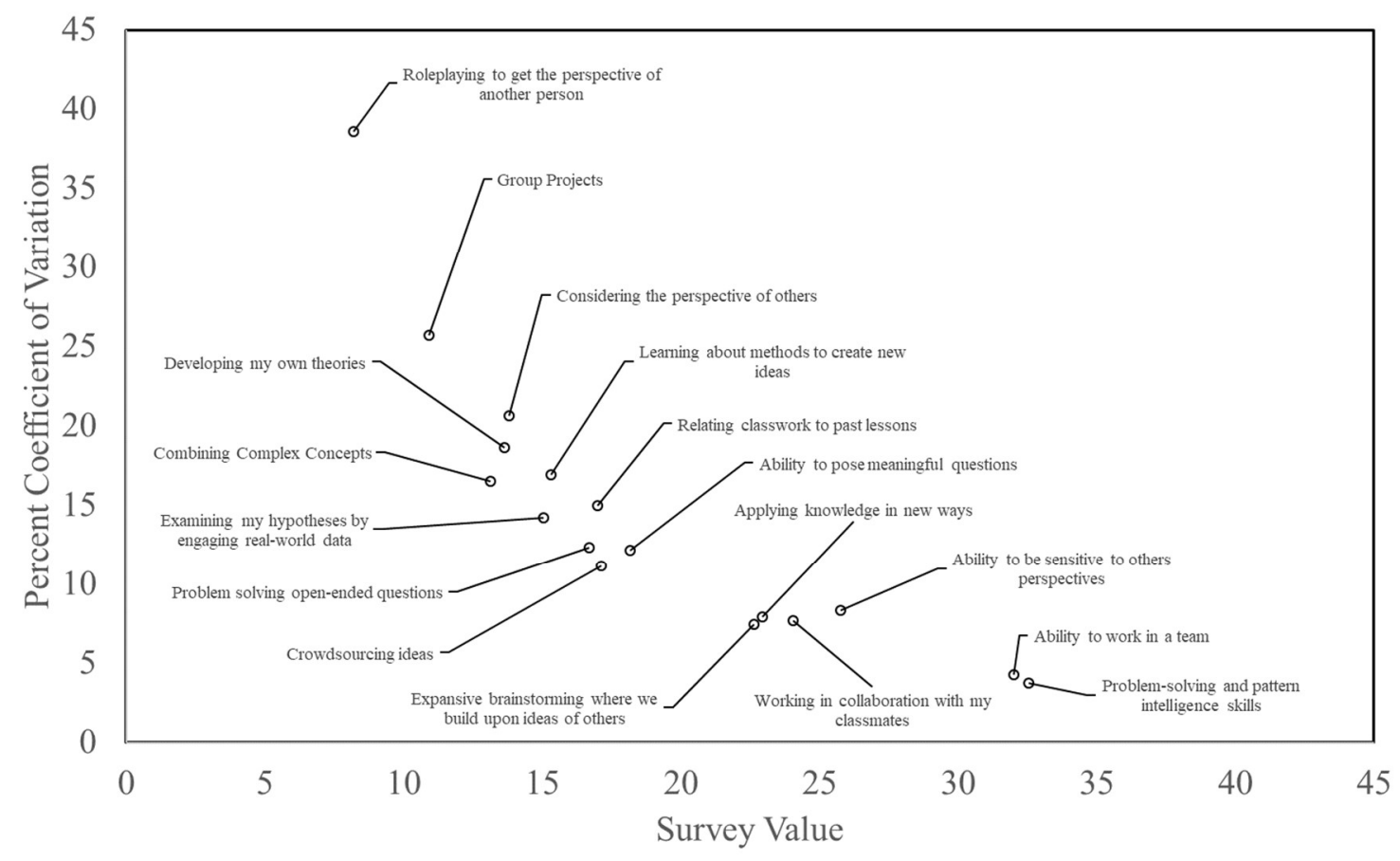

Figure 6-Breakdown of Active Learning - Liberal Arts - Engineering Survey Elements

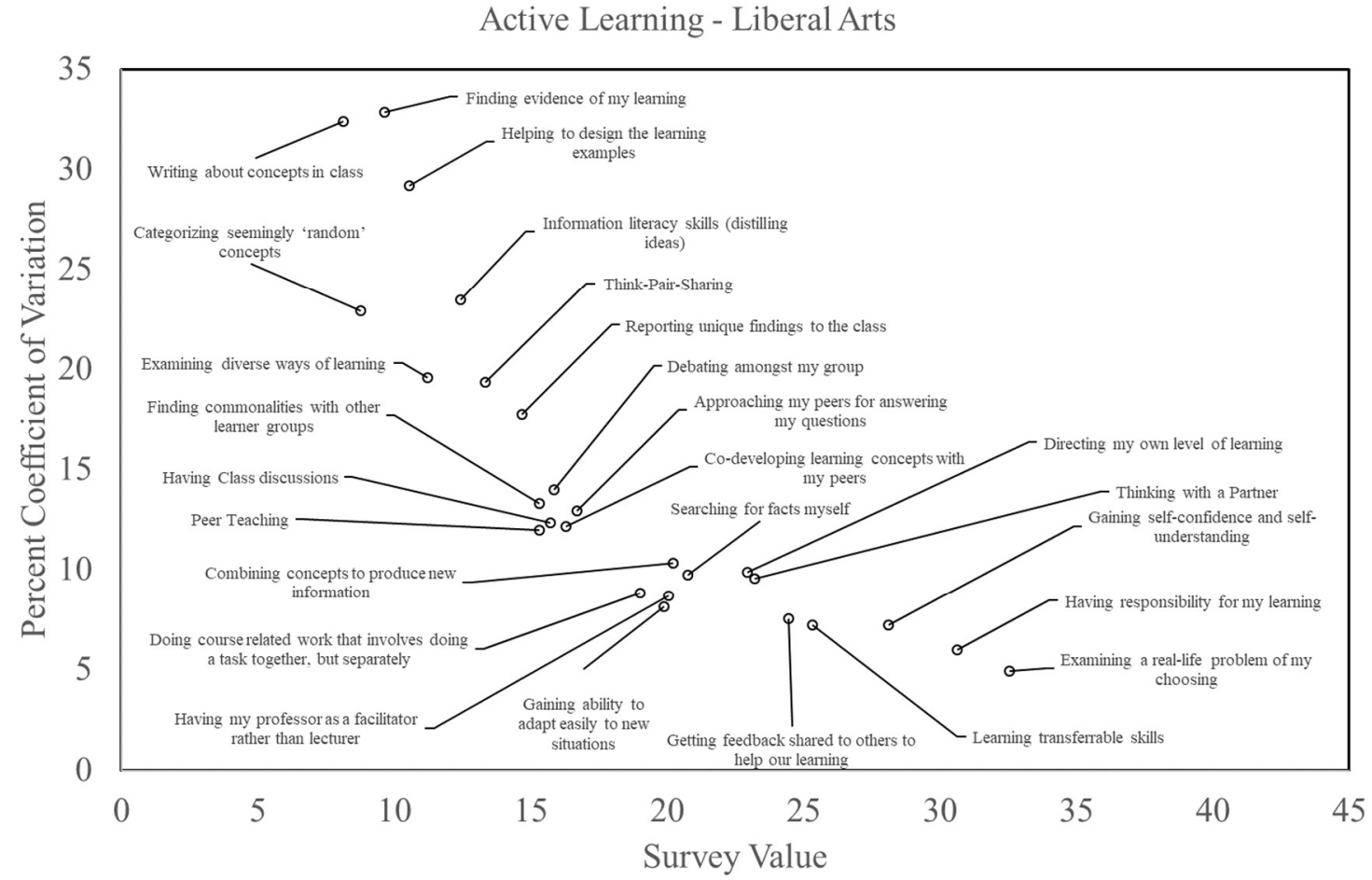

Figure 7 -Breakdown of Active Learning - Liberal Arts Survey Scores 
Engineering - Active Learning

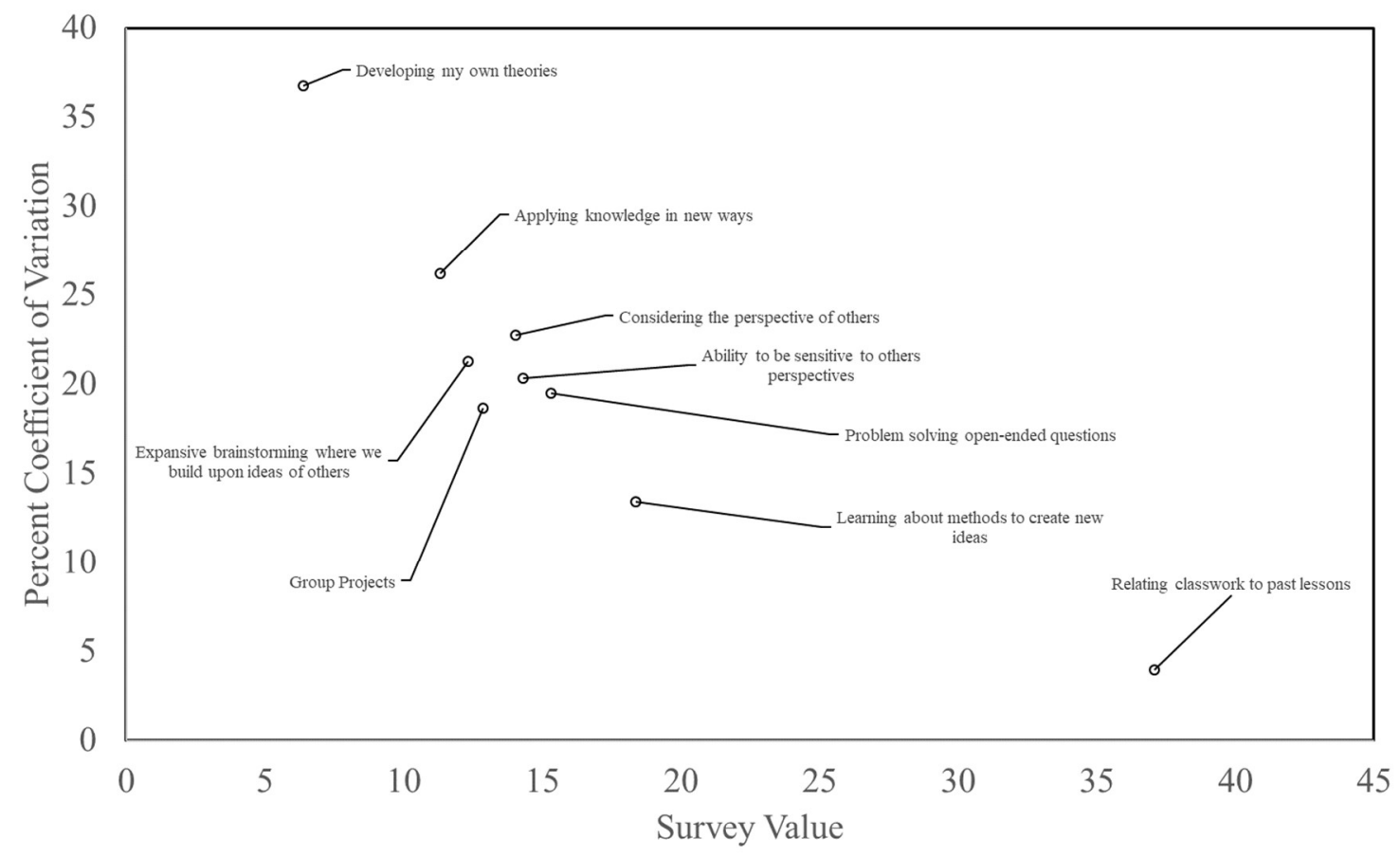

Figure 8-Breakdown of Engineering - Active Learning Survey Elements

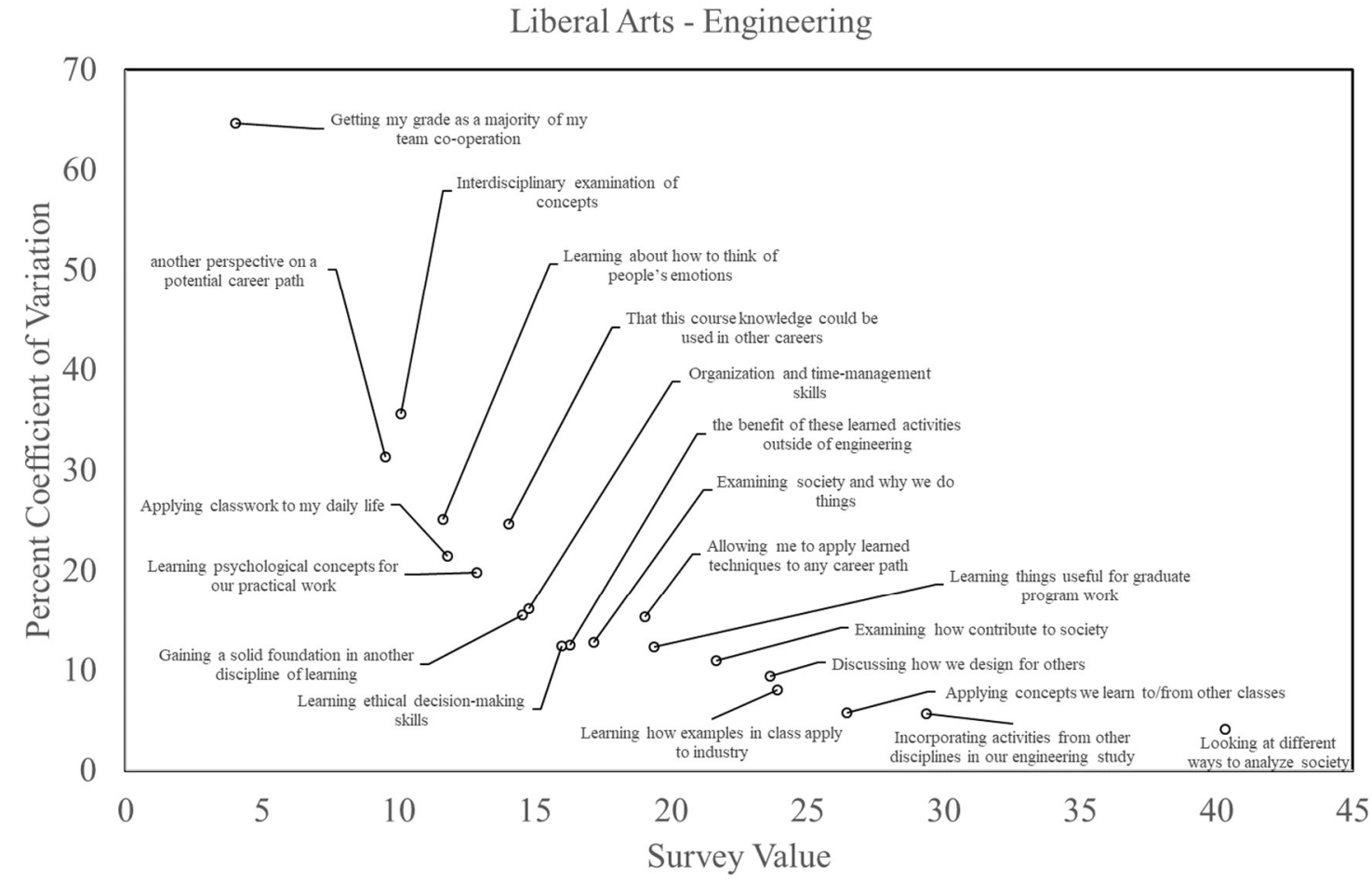

Figure 9-Breakdown of Liberal Arts - Engineering Survey Elements 
Active Learning

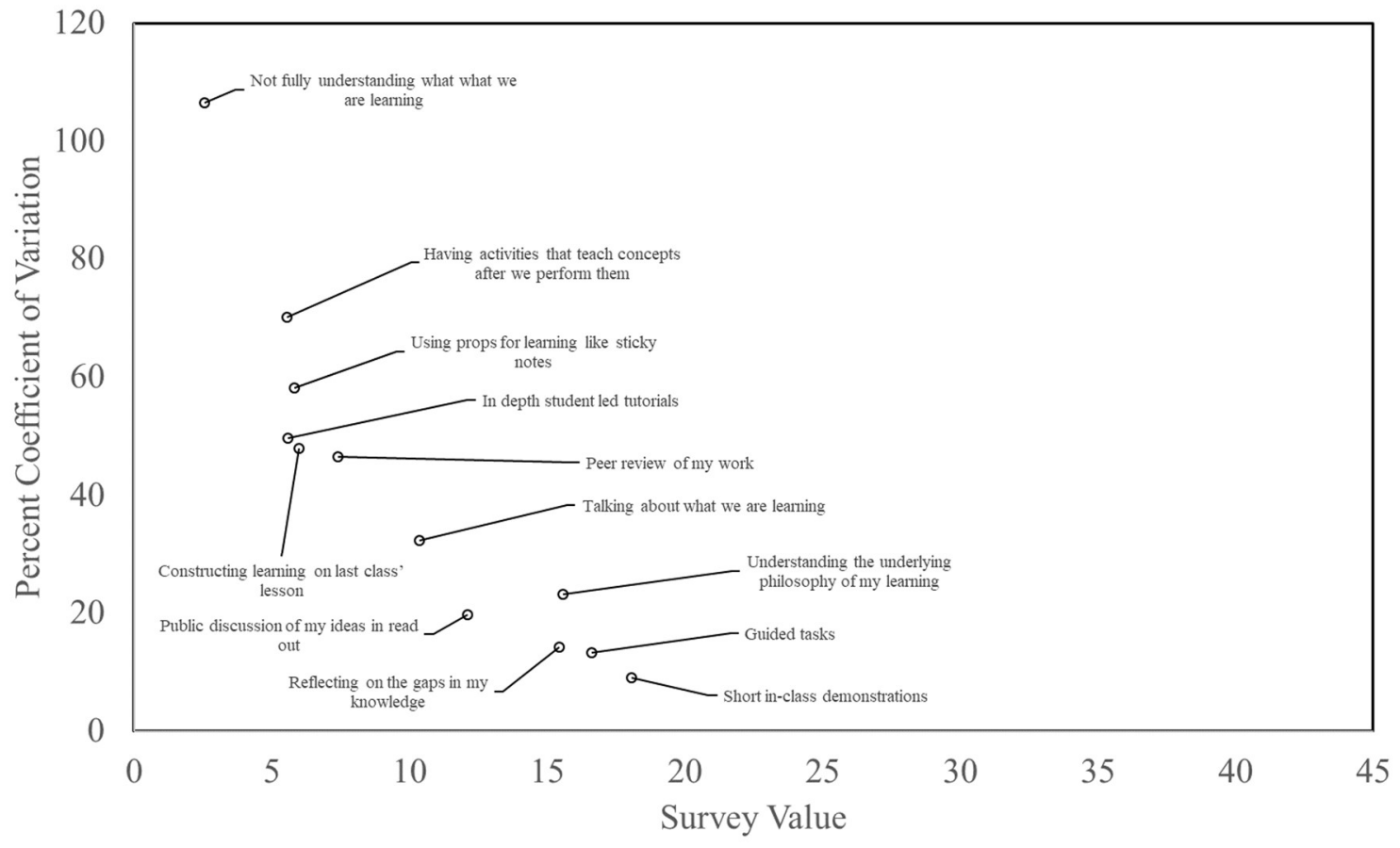

Figure 10-Breakdown of Active Learning Survey Elements

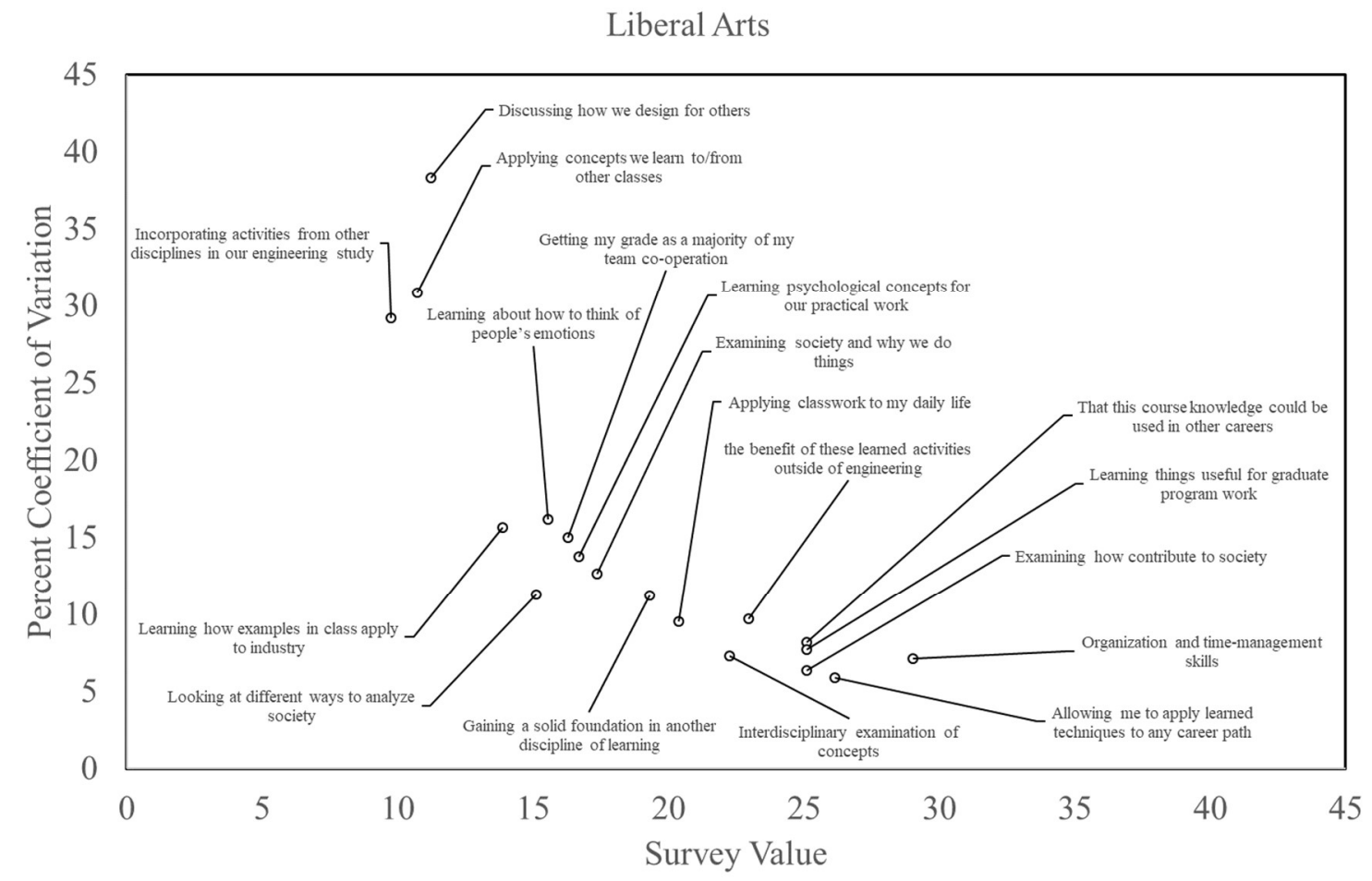

Figure 11 -Breakdown of Liberal Arts Survey Elements 
Engineering

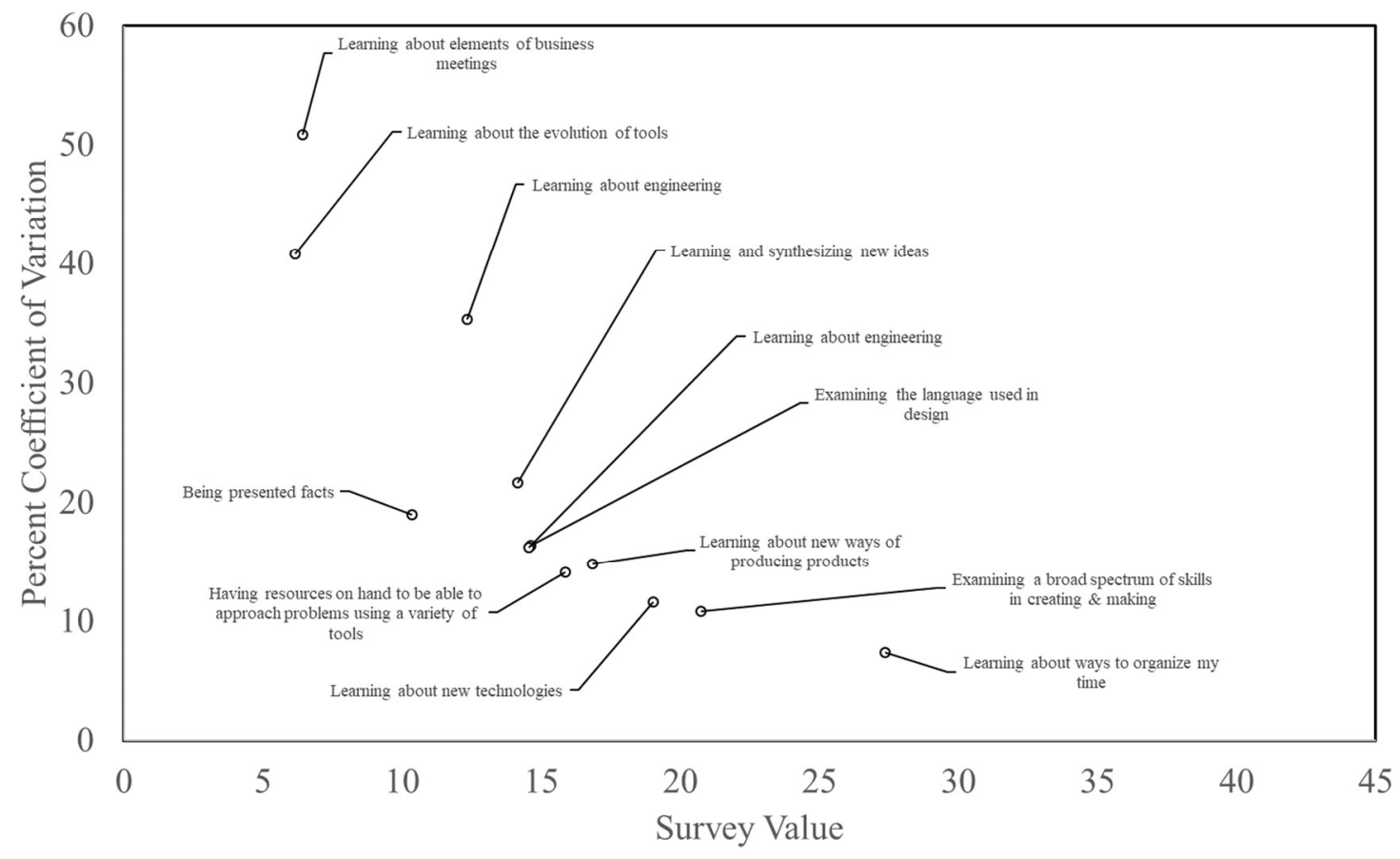

Figure 12-Breakdown of Engineering Survey Elements 